\title{
THE RELATIONSHIP
}

\section{BETWEEN PSYCHOSOCIAL RISKS AND OCCUPATIONAL FUNCTIONING AMONG MINERS}

\author{
AGNIESZKA MOŚCICKA-TESKE ${ }^{1}$, JOANNA SADŁOWSKA-WRZESIŃSKA², ANNA NAJDER², \\ and MARCIN BUTLEWSKI ${ }^{2}$
}

\author{
${ }^{1}$ University of Social Science and Humanities, Faculty in Poznan, Poznań, Poland \\ Department of Clinical and Health Psychology \\ ${ }^{2}$ Poznan University of Technology, Poznań, Poland \\ Department of Ergonomics and Quality Management \\ ${ }^{3}$ Nofer Institute of Occupational Medicine, Łódź, Poland \\ Department of Health and Work Psychology
}

\begin{abstract}
Objectives: This paper presents the results of research on the scale of psychosocial risks among miners. A comparative analysis was made, comparing the research results with the data obtained from workers in the following industries: metal, energy, chemical and construction - along with an indication of the relationship between stressful working conditions and the occupational functioning of the respondents. Material and Methods: The study involved 483 adults employed in mines in Poland. The study on psychosocial risks in the workplace was performed using Psychosocial Risk Scale, developed by the Department of Health and Work Psychology of the Nofer Institute of Occupational Medicine, Łódź, Poland. Psychosocial Risk Scale is the scientifically validated diagnostic tool and is characterized by high reliability and validity of coefficients. Results: The analysis of differences in occupational functioning between miners and other workers in heavy industry provides that miners are in general more healthy, less stressed, more positive emotionally and normatively committed to work, more satisfied with work, and more stable in the employment (as opposite to turnover intention) than the other workers. The results suggest that miners with a lower level of stress functioned at work better - they evaluated their health and ability to work better than miners with a higher level of stress. Their intention to change a job was lower than among those experiencing more stress. The most pronounced effect was observed for the influence on this dimension of functioning by job context risks (the higher level of probability, and the higher t-test value). Conclusions: Occupational functioning of miners in Poland is better than the other employees in heavy industry. The analysis of differences in occupational functioning dimensions provides that a lower level of psychosocial risk in a workplace is connected with a higher level of job satisfaction, positive affective and normative work commitment and a lower level of turnover intension. Int J Occup Med Environ Health. 2019;32(1):87-98
\end{abstract}

Key words:

job satisfaction, miners, occupational stress, psychosocial risk factors, work engagement, turnover

\footnotetext{
Funding: this work was supported by the European Union within the framework of the European Social Fund (grant No. POKL.02.01.02-00-031/10 entitled "The impact of the improvement of working conditions on the reduction of economic costs in companies going through modernization and adaptation processes - research project," grant manager: Maria Żytko, M.A.).

Received: November 24, 2016. Accepted: May 14, 2018.

Corresponding author: Agnieszka Mościcka-Teske, University of Social Science and Humanities, Faculty in Poznan, Department of Clinical and Health Psychology, Kutrzeby 10, 61-719 Poznań, Poland (e-mail: amoscicka-teske@swps.edu.pl).
} 


\section{INTRODUCTION}

\section{Specific characteristics of the mining profession}

The heavy industry segment is directly affected by dominating global trends, technological advances and environmental changes. Significant trends include population growth and urbanization, which increase the demand for raw materials and new investments in infrastructure. Among environmental trends, there is a need for pollution control and regulations concerning energy consumption and the safety of raw material extraction. The dynamics of these changing processes increasingly contributes to an excessive psychological burden on employees, which is currently one of the greatest problems of modern workplaces.

Psychological stress is the result of both technical and organizational factors and it also depends on the individual characteristics of employees. For this reason, in order to define the relationship between technical-organizational (ergonomic) work factors and the perceived welfare of workers, the study must contain a large research sample and a comparison with quantitative indicators relevant to a given industry [1].

The stress analysis in the mining industry as an independent research topic is the subject of relatively few publications [2] and is most commonly undertaken in addition to other subjects, mainly focused on work safety culture and workplace accident analysis [3-5]. Studies show that the most serious workplace accidents occur in the industrial manufacturing and construction sectors [6]. According to both national and global research, the bituminous coal mining industry is characterized by the greatest risk of workplace accidents [7-11]. This situation arises due to unique working conditions in this sector and is associated with the occurrence of virtually all natural hazards. However, in recent years there is a noticeable, significant increase in accidents caused by the human factor. Personal safety hazards arise mainly from:
- using incorrect, dangerous work methods,

- non-compliance with regulations, instructions and legislation,

- supervisor tolerance of work performance contrary to safety requirements,

- hiring workers lacking the necessary qualifications or authorization,

- the insufficiency or lack of required personal protective equipment [12].

Information on workplace accidents, excluding individual farms, is obtained from statistical accident cards (Statystyczna karta wypadku - Z-KW). The accident documentation includes information about the general cause of the accident, which may be e.g., improper conduct of the employee but unfortunately it does not provide information on the reasons of the inappropriate conduct. Therefore, it seems important to adopt a broader perspective in the workplace accident research, to include data on the occupational functioning of employees. It is believed that job stress is a direct or indirect cause of the majority of workplace accidents.

\section{Job characteristics and psychosocial risks}

The mining profession, regarded as a difficult and dangerous occupation because it is a threat to life and health [13], requires exceptional physical and mental fitness. This risk is related to both the nature of the performed work and the physical hazards in the workplace, as well as the large mental and physical burden and the specific predisposition required for operating devices.

The work environment of a mine is associated with unique working conditions which constitute a source of hazards for miners. The most common hazards include:

- lack of natural light,

- uncomfortable (cramped) work space,

- air quality consists of high humidity, particle pollution, decreased oxygen levels, mine gas contamination, 
- constant air flow (in surface excavations - up to $5 \mathrm{~m} / \mathrm{s}$, in drift mining - up to $8 \mathrm{~m} / \mathrm{s}$, in shafts and during transport - up to $12 \mathrm{~m} / \mathrm{s}$ ),

- increased air pressure due to depth,

- constant change in work place (resulting from the movement of mine face and maintenance),

- alterations in rock mass structure (which results in falling rocks),

- leaks or condensation from the roof,

- incline of seams and excavations carried out in them,

- noise and vibration of machines and equipment used for extraction and haulage,

- heat,

- high transport traffic in excavations limited in size and number,

- natural hazards (rock burst, methane, fire, explosions of methane and coal dust, outbursts of gases, rocks and others),

- physical fatigue of workers [12].

Stress plays an important role in the context of occupational functioning. Stress reactions are caused by certain stimuli (stressors) which may be physical, psychological, emotional or others, coming from the external environment or the employee itself [14]. A miner exposed to stress suffers from changes in the circulatory system: has an increased heart rate and blood pressure. The increased heart rate due to stress is added to the already increased heart rate due to physical effort, and as a result it often exceeds twice the normal value. A heart rate $130 \mathrm{bpm}$ results in less efficient work, a decreased force of heart contraction and inefficient blood flow. Additionally, stress increases the secretion of hormones responsible for metabolism. An increased metabolism results in increased heat production by the body. This situation is all the more undesirable due to high ambient temperatures that put additional pressure on the cardiovascular and thermoregulatory systems, which leads to reduced physical abilities and affects worker behavior [14].
Psychosocial risks and their impact on the safety and functioning of humans at work, as well as on the functioning of whole organizations, are one of the most current areas of interest of Polish and international institutions and organizations concerned with the health and safety of employees. The European Agency for Safety and Health at Work (EU-OSHA) points out that existing and "new and emerging psychosocial risks" are the most current threats to employees, highlighting the rising level of risk $[15,16]$. Occupational stress affects the health and well-being of individuals and the functioning of the whole organization $[17,18]$. From the perspective of the individual employee, increased psychological stress leads to a decrease in the quality of work performance, reduces work motivation, satisfaction and commitment and increases the risk of burnout. It also leads to riskier behavior, such as, for example, drinking alcohol in the workplace. At the organizational level, increased psychological stress causes resistance to change, high rates of sickness absence, strikes and riots, lack of productivity and increased absenteeism and staff fluctuation [15,17,19-21].

\section{MATERIAL AND METHODS}

This paper shows the results of research on psychosocial risks among miners. A comparative analysis was made using data obtained from workers in the following industries: metal, energy, chemical and construction - along with an indication of the relationship between stressful working conditions and the occupational functioning of the workers.

The study on psychosocial risks in the workplace was performed using the Psychosocial Risk Scale (PRS), which is the validated diagnostic tool and is characterized by a high reliability and validity of coefficients [22]. The PRS evaluates the prevalence of job characteristics that may be potential hazards and assesses the stress they potentially cause. The PRS takes into account the so-called general stressors that may occur regardless of the industry in which the analyzed person 
is employed as well as the specificity of psychosocial risks in a given sector of the economy (e.g., in mining, energy).

It also enables one to assess an employee's days of absenteeism, frequency and the number of accidents at work, health status and ability to work, 7 aspects of work satisfaction (type of work, organization of work, working conditions, salary and benefits, opportunities for career development, relationships with superiors, relationships with peers/colleagues), occupational commitment and turnover intention. The scale consists of 4 parts (A-D):

1. Part A refers to demographic data (such as age, gender, seniority, position, etc.).

2. Part B contains questions related to days of absenteeism, frequency and the number of accidents at work, health status and ability to work, the 7 aforementioned aspects of work satisfaction, occupational commitment and turnover intention.

3. Part $\mathrm{C}$ consists of 50 statements related to work features that pose potential psychosocial risks. These features are grouped into 3 factors: job content, job context and pathologies in job relationships, which in turn consist of bundles of questions belonging to 9 psychosocial dimensions of the work environment identified in the Cox theory (content of the work, the time frame of work, workload, control, culture and functions of the organization, interpersonal relations, the role in the organization or responsibility, career development, work-home relationship) [15]. The internal consistency of the whole scale measured by Cronbach's $\alpha$ is 0.94 .

4. Part D of the PRS (the so-called PRS branch annex) is a set of items concerning the characteristics of specific professions in the given economy sector. The D-PRS Annex for the mining industry includes 12 questions (Cronbach's $\alpha=0.8$ ).

The subjects refer to each of the work characteristics in 2 dimensions:

- whether a given feature is present or not present in their workplace,
- if the feature exists, to what extent it is stressful (not at all, a little, or very much).

In the part assessing commitment - the higher the score in the category of "affective commitment" - the stronger the positive emotional involvement; the higher the score in the category of "continuance commitment" - the stronger this kind of commitment is; the higher the score in the category of "normative commitment" - the stronger the normative commitment is.

The data was analyzed with the use of Pearson's correlation and the t-test (the variables had a normal distribution, and the Leaven's test was controlled).

After literature review, 4 hypotheses were assumed:

5. Miners will have a higher level of health and occupational functioning in comparison with other heavy industry professionals.

6. There will be a lower level of occupational stress among miners in comparison with other heavy industry professionals.

7. A higher level of occupational stress will be connected with a lower health status, ability to work, and turnover intention.

8. A higher level of occupational stress will be connected with a lower level of emotional commitment and a higher level of continuance and normative commitment.

The latter will also be connected with a lower level of job satisfaction.

\section{Sample}

The study sample involved 483 adults employed in mines in Poland, out of which $87.8 \%$ were men. The average age in the study group was 40.49 years old $(\mathrm{SD}=8.9$ ). The vast majority of respondents in this sector were miners and miner foremen ( $\mathrm{N}=213,44 \%)$, locksmiths $(\mathrm{N}=63,13 \%)$, and machine operators $(\mathrm{N}=26,6 \%)$. The average professional experience duration at the current position was 20.42 years (min. 1 year and max 45 years of job tenure). 


\section{RESULTS}

The results refer to the frequency of exposure of the studied miners to the occurrence of stressful workplace factors. Among 50 studied potential sources of stress, 15 were indicated as the most frequently occurring in the respondents' workplaces and the most stressful. The Table 1 presents the data on the occurrence and stressfulness of the selected work features.

The analysis of the differences in occupational functioning between miners and other workers in heavy industry indicates that miners were healthier, less stressed and more satisfied with their work. Miners were more emotionally and normatively committed to their work and more stable in their employment (as opposed to the turnover intention) than other workers. Only one variable has a negative connotation for miners - considering the last 12 months before the study, they were involved in more accidents than other employees in heavy industry (Table 2).

To verify the hypothesis concerning the differences in occupational functioning of miners caused by their level of stress resulting from psychosocial risks, the study group was divided into 2 groups - a low level and a high level of stress.

The hypothesis was concerned with differences in health status, ability to work, and turnover intention between miners with low stress and high stress caused by each type

Table 1. The most often occurring and most stressful work features for miners [22] $(\mathrm{N}=483)$

\begin{tabular}{lcc}
\hline \multicolumn{1}{c}{ Item content } & $\begin{array}{c}\text { Occurrence } \\
{[\mathrm{n}(\%)]}\end{array}$ & $\begin{array}{c}\text { Stressfulness } \\
{[\mathrm{n}(\%)]}\end{array}$ \\
$\begin{array}{l}\text { "My job requires complying with strictly specified procedures" } \\
\text { "My job requires prolonged attention" }\end{array}$ & $444(91.9)$ & $356(80.2)$ \\
$\begin{array}{l}\text { "My job, for most of the time, requires readiness to respond } \\
\text { quickly" }\end{array}$ & $440(91.1)$ & $368(83.6)$ \\
"My work is often controlled (internal and external audits, & $436(90.3)$ & $371(85.1)$ \\
inspections, quality control, etc.)" & $404(83.6)$ & $322(79.7)$ \\
"My job performance and its quality depend on whether and & & $354(88.1)$ \\
how my predecessors did it earlier" & $402(83.2)$ & $290(73.1)$ \\
"Availability is required in my job" & & $301(76.8)$ \\
"My job requires using new technologies" & $397(82.2)$ & $309(84.9)$ \\
"I work in particularly difficult physical conditions" & $392(81.2)$ & $263(80.7)$ \\
"Possibilities for promotion are limited in my job" & $364(75.4)$ & $270(83.3)$ \\
"There is a threat of dismissals in my work" & $326(67.5)$ & $248(82.7)$ \\
"I often have to perform my job despite the lack of suitable \\
means (for example, tools or materials)"
\end{tabular}


Table 2. Differences in occupational functioning and psychosocial risk between miners and other workers in heavy industry (t-test results)

\begin{tabular}{|c|c|c|c|}
\hline \multirow{2}{*}{ Variable } & \multicolumn{2}{|c|}{$\begin{array}{l}\text { Difference in occupational functioning } \\
\text { and psychosocial risk } \\
\text { (M) }\end{array}$} & \multirow{2}{*}{$\mathrm{t}$} \\
\hline & $\begin{array}{c}\text { miners } \\
(\mathrm{N}=483)\end{array}$ & $\begin{array}{l}\text { other workers } \\
\text { in heavy industry } \\
(\mathrm{N}=1966)\end{array}$ & \\
\hline Accidents at work [n] & 0.10 & 0.06 & $2.620 * *$ \\
\hline Sick leaves [n] & 0.64 & 0.74 & n.s. \\
\hline Absence [days] & 8.43 & 8.22 & n.s. \\
\hline Self-evaluated health status & 3.88 & 3.73 & $3.366^{* * *}$ \\
\hline Self-evaluated ability to work & 3.65 & 3.66 & n.s. \\
\hline Turnover intention & 1.96 & 2.38 & $-8.395^{* * *}$ \\
\hline \multicolumn{4}{|l|}{ Occurrence of: } \\
\hline job content risks & 0.77 & 0.78 & n.s. \\
\hline job context risks & 0.51 & 0.57 & $-3.654^{* * *}$ \\
\hline pathologies in job relationships & 0.19 & 0.18 & n.s. \\
\hline \multicolumn{4}{|l|}{ Stressfulness of: } \\
\hline job content risks & 2.07 & 2.18 & $-4.216^{* * *}$ \\
\hline job context risks & 1.91 & 2.06 & $-6.861^{* * *}$ \\
\hline pathologies in job relationships & 1.83 & 1.95 & $-2.871^{* *}$ \\
\hline branch specific risks & 1.18 & 1.29 & $-3.140 * *$ \\
\hline shift work (miners $\mathrm{N}=334$ ) & 2.21 & 2.23 & n.s. \\
\hline Self-evaluation of work engagement & 3.94 & 3.90 & n.s. \\
\hline \multicolumn{4}{|l|}{ Commitment } \\
\hline positive affective & 3.22 & 2.98 & $5.580^{* * *}$ \\
\hline continuance & 2.74 & 2.98 & $-4.470^{* * *}$ \\
\hline normative & 2.57 & 2.38 & $3.693^{* * *}$ \\
\hline \multicolumn{4}{|l|}{ Satisfaction with: } \\
\hline type of work & 2.99 & 2.87 & $3.452 * * *$ \\
\hline organization of work & 2.67 & 2.43 & $6.512^{* * *}$ \\
\hline working conditions & 2.43 & 2.28 & $3.363^{* * *}$ \\
\hline salary & 2.43 & 2.20 & $5.384 * * *$ \\
\hline career development & 2.68 & 2.31 & $9.480 * * *$ \\
\hline relationship with superiors & 2.89 & 2.66 & $6.133^{* * *}$ \\
\hline relationship with colleagues & 3.42 & 3.29 & $4.136^{* * *}$ \\
\hline General job satisfaction & 2.79 & 2.58 & $7.841^{* * *}$ \\
\hline
\end{tabular}

${ }^{*} \mathrm{p}<0.05 ; * \mathrm{p}<0.01 ; * * \mathrm{p}<0.001$.

n.s. - non significant difference. 
of psychosocial risk. The results (Table 3) suggest that miners with lower stress functioned better at work - they assessed their health status and ability to work as higher than miners with higher stress. Their intention to change jobs was also lower than among those experiencing more stress. The most pronounced effect was observed in the influence of this dimension of functioning on job context risks (the higher level of probability, and the higher t-test value).

The third hypothesis concerned work engagement and occupational commitment. The results reveal (Table 4) that there were no significant differences in work engagement between miners with low and high levels of stress. The lack of differences in this area could be explained by the use of self-evaluation in assessing engagement and the need to maintain a high self-image. However, a deeper analysis of the components of engagement discovered significant differences in this area, depending on the level of oc- cupational stress. The main motivation for commitment among miners with lower stress was positive emotional and normative commitment, based on job context (positive emotional commitment) and branch specific stressors (normative commitment). In the group of miners, strong differences may be observed in the area of continuance commitment, dependent on all kinds of work stress. The highly stressed miners indicated that their main motivation for working in the mine was that they had to work somewhere. This is the weakest and most short-lived source of motivation to work.

The last hypothesis concerned the level of job satisfaction and its dependence on occupational stress. The results in the Table 5 show that job satisfaction among miners is strong, and multileveled-connected with the level of their occupational stress. All 7 dimensions of satisfaction were significantly differentiated by the level of stress.

Table 3. Differences in health status, ability to work, and turnover intention among miners with low stress and high stress caused by psychosocial risks (t-test results)

\begin{tabular}{llll}
\hline \multicolumn{1}{c}{ Dependent/Grouping variable } & \multicolumn{2}{c}{ Stress } & \multirow{2}{*}{$\mathrm{t}$} \\
\cline { 2 - 3 } & low & high & \\
\hline Self-evaluation of health status & & & $-3.048^{* *}$ \\
job context & 4.00 & 3.77 & $-2.473^{* *}$ \\
job content & 3.98 & 3.79 & $-2.901^{* *}$ \\
branch specific stressors & 3.98 & 3.76 & $-2.572^{* *}$ \\
$\quad$ total stress & 3.98 & 3.79 & \\
Self-evaluation of ability to work & & & $-2.181^{*}$ \\
job context & 3.73 & 3.57 & n.s. \\
job content & 3.70 & 3.61 & n.s. \\
branch specific stressors & 3.68 & 3.61 & n.s. \\
total stress & 3.68 & 3.62 & \\
Turnover intention & & & $4.587^{* * *}$ \\
job context & 1.75 & 2.14 & n.s. \\
job content & 1.96 & 1.95 & n.s. \\
branch specific stressors & 1.91 & 2.01 & $3.060^{* *}$ \\
total stress & 1.81 & 2.08 & \\
\hline
\end{tabular}

$* \mathrm{p}<0.05 ;{ }^{* *} \mathrm{p}<0.01 ;{ }^{* * *} \mathrm{p}<0.001$.

n.s. - non significant difference. 
Table 4. Differences in occupational commitment among miners with low stress and high stress caused by psychosocial risks (t-test results)

\begin{tabular}{|c|c|c|c|}
\hline \multirow{2}{*}{ Dependent/Grouping variable } & \multicolumn{2}{|c|}{ Stress } & \multirow{2}{*}{$\mathrm{t}$} \\
\hline & low & high & \\
\hline \multicolumn{4}{|l|}{ Self-evaluation of work engagement } \\
\hline job context & 3.95 & 3.92 & n.s. \\
\hline job content & 3.94 & 3.94 & n.s. \\
\hline branch specific stressors & 3.98 & 3.90 & n.s. \\
\hline total stress & 3.94 & 3.94 & n.s. \\
\hline \multicolumn{4}{|l|}{ Positive affective commitment } \\
\hline job context & 3.31 & 3.13 & $-2.419 * *$ \\
\hline job content & 3.20 & 3.23 & n.s. \\
\hline branch specific stressors & 3.28 & 3.15 & n.s. \\
\hline total stress & 3.26 & 3.18 & n.s. \\
\hline \multicolumn{4}{|l|}{ Continuance commitment } \\
\hline job context & 2.40 & 3.04 & $6.555^{* * *}$ \\
\hline job content & 2.45 & 2.96 & $5.244^{* * *}$ \\
\hline branch specific stressors & 2.48 & 3.03 & $5.748^{* * *}$ \\
\hline total stress & 2.47 & 2.96 & $4.998^{* * *}$ \\
\hline \multicolumn{4}{|l|}{ Normative commitment } \\
\hline job context & 2.51 & 2.63 & n.s. \\
\hline job content & 2.49 & 2.64 & n.s. \\
\hline branch specific stressors & 2.49 & 2.67 & $1.952^{*}$ \\
\hline total stress & 2.51 & 2.63 & n.s. \\
\hline
\end{tabular}

${ }^{*} \mathrm{p}<0.05 ;{ }^{* *} \mathrm{p}<0.01 ; * * \mathrm{p}<0.001$

n.s. - non significant difference.

Table 5. Differences in work satisfaction among miners with low stress and high stress caused by psychosocial risks (t-test results)

\begin{tabular}{lccc}
\hline & Satisfaction & \multicolumn{3}{c}{ Stress } & \multirow{2}{*}{ t } \\
\cline { 2 - 3 } & low & high & \\
\hline In general & & & \\
job context & 2.89 & 2.69 & $-4.264^{* * *}$ \\
job content & 2.89 & 2.71 & $-3.738^{* * *}$ \\
branch specific stressors & 2.91 & 2.66 & $-5.181^{* * *}$ \\
total stress & 2.88 & 2.71 & $-3.604^{* * *}$ \\
\hline
\end{tabular}


Table 5. Differences in work satisfaction among miners with low stress and high stress caused by psychosocial risks (t-test results) - cont.

\begin{tabular}{|c|c|c|c|}
\hline \multirow{2}{*}{ Satisfaction } & \multicolumn{2}{|c|}{ Stress } & \multirow{2}{*}{$\mathrm{t}$} \\
\hline & low & high & \\
\hline \multicolumn{4}{|l|}{ Type of work } \\
\hline job context & 3.05 & 2.93 & $-1.975^{*}$ \\
\hline job content & 3.07 & 2.93 & $-2.288^{*}$ \\
\hline branch specific stressors & 3.07 & 2.89 & $-3.022 * *$ \\
\hline total stress & 3.05 & 2.94 & n.s. \\
\hline \multicolumn{4}{|l|}{ Organization of work } \\
\hline job context & 2.80 & 2.56 & $-3.755^{* * *}$ \\
\hline job content & 2.77 & 2.60 & $-2.631^{* *}$ \\
\hline branch specific stressors & 2.80 & 2.53 & $-4.086^{* * *}$ \\
\hline total stress & 2.79 & 2.58 & $-3.153^{* *}$ \\
\hline \multicolumn{4}{|l|}{ Working conditions } \\
\hline job context & 2.53 & 2.34 & $-2.433^{* *}$ \\
\hline job content & 2.58 & 2.32 & $-3.133^{*}$ \\
\hline branch specific stressors & 2.63 & 2.22 & $-5.153^{* * *}$ \\
\hline total stress & 2.53 & 2.34 & $-2.421^{*}$ \\
\hline \multicolumn{4}{|l|}{ Salary } \\
\hline job context & 2.53 & 2.33 & $-2.586 * *$ \\
\hline job content & 2.59 & 2.32 & $-3.391^{* * *}$ \\
\hline branch specific stressors & 2.59 & 2.26 & $-4.227^{* * *}$ \\
\hline total stress & 2.55 & 2.34 & $-2.640 * *$ \\
\hline \multicolumn{4}{|l|}{ Career development } \\
\hline job context & 2.84 & 2.54 & $-4.309^{* * *}$ \\
\hline job content & 2.74 & 2.63 & n.s. \\
\hline branch specific stressors & 2.74 & 2.61 & $-1.913^{*}$ \\
\hline total stress & 2.78 & 2.60 & $-2.527^{*}$ \\
\hline \multicolumn{4}{|l|}{ Relationship with colleagues } \\
\hline job context & 2.47 & 2.37 & n.s. \\
\hline job content & 3.49 & 3.37 & $-2.243^{*}$ \\
\hline branch specific stressors & 3.47 & 3.36 & $-2.163^{*}$ \\
\hline total stress & 3.46 & 3.38 & n.s. \\
\hline \multicolumn{4}{|l|}{ Relationship with superiors } \\
\hline job context & 3.03 & 2.76 & $-3.043^{* *}$ \\
\hline job content & 3.01 & 2.80 & $-3.985^{* * *}$ \\
\hline branch specific stressors & 3.03 & 2.74 & $-4.310^{* * *}$ \\
\hline total stress & 3.03 & 2.78 & $-3.682^{* * *}$ \\
\hline
\end{tabular}

$* \mathrm{p}<0.05 ; * \mathrm{p}<0.01 ; * * * \mathrm{p}<0.001$.

n.s. - non significant difference. 


\section{DISCUSSION}

Miners experienced high strain at work and they are at increased risk of stress. According to the results, a higher level of stress was associated with a lower emotional occupational commitment. The analysis of the sources of stress showed that weak emotional commitment was most strongly associated with the stressfulness of context factors (soft factors, such as control, organizational culture, interpersonal relationships, role in organization, responsibility, career development, and home-work relations).

Similar relations were observed regarding continuance commitment - higher rates were connected with a higher level of stressfulness of psychosocial factors (both the context and content of the job). The relationship between occupational stress and normative commitment was observed only in relation to the stressors specific for mining. These results confirm the findings of other authors analyzing similar dimensions of human functioning in the workplace. Tiwari and Mishra [23] have shown unequivocal negative correlations between professional stress and all dimensions of engagement. Michael et al. [24] and Nasr [25] also have discovered the relationship between increased levels of occupational stress and lower emotional commitment, with the increased level of continuance commitment.

Some results suggest that workers' greater involvement and/or dedication to their work may reduce stress and increase job satisfaction. Moreover, increased work involvement reduces role conflict. Accordingly, employees who perceive that other workers are highly involved are more satisfied with their job. These results indicate the benefits of employee dedication in their work efforts [26].

In comparison to other workers, the studied miners reported experiencing more accidents at work. Despite the fact that about $80-90 \%$ of accidents in coal mines are caused by human factors [27], there is no doubt that work accidents or injuries and near misses are related to the working conditions in mines, for instance, mining equip- ment negatively influences the safety experience of employees. If heavy machinery necessary in modern mining is not offered, older equipment becomes a direct threat to mine workers' safety [28]. However, in comparison to employees with adequate work demands and work control, employees with high workloads, unclear roles and no or low control over their responsibilities reported more near misses. What is more, $70.2 \%$ of coal miners who experienced at least one occupational injury, were unsatisfied with the coal mining job [29]. Knowing this, the supervisors should seek to address the problem of striking the right balance between work demands, work pace and workload [28]. Work accidents are ordinarily associated with an attitude towards a low value of life, psychological fatigue and emotional instability [30].

A significant relationship was observed between job satisfaction and stress levels - the respondents experienced higher levels of stress which lowered their level of job satisfaction. This dependence was observed in all 7 dimensions of work satisfaction included in this study. It is a very promising result taking into consideration the fact that low job satisfaction is considered as an emotional response to job strain. Job dissatisfaction together with poor perception of working conditions, poor management and supervision and job stress play an evident role in occupational injuries [31]. It should also be noted that coal miners' job satisfaction mediates the impact of routinization, promotion opportunities, work overload, positive and negative affectivity on life satisfaction [32]. Job satisfaction is a predictor of returning to work after an injury [33]. Authors suggest that greater satisfaction may protect miners against stress consequences and turnover intention.

\section{CONCLUSIONS}

As expected, a lower stress level is associated with greater satisfaction with interpersonal relationships. Studies show that poor interpersonal relationships cause greater working pressure, while a balanced relationship supports a pleas- 
ing atmosphere at work and produces low working pressure $[33,34]$. Social support at work is presumably not elicited only when stressors are encountered but also if an individual may count on social support, it mitigates the occurring strains. Thus, good/friendly interpersonal relationships reduce the level of stress experienced. It is likely that social support acts in 2 more ways. Except for reducing stress, social support also alleviates the strength of the stressors themselves as well as the consequences of the stress experienced [34]. Work context perception influences employee outcomes. Among other factors, the level of support from supervisors and work stress have significant and essential effects on job performance and satisfaction [26].

\section{REFERENCES}

1. Mościcka-Teske A, Sadłowska-Wrzesińska J, Butlewski M, Misztal A, Jacukowicz A. Stressful work characteristics, health indicators and work behavior. The case of machine operators. Int J Occup Saf Ergon. 2017;23(4):510-8, https://doi. org/10.1080/10803548.2016.1197577.

2. Grodzicka A. [Stress analysis in mining sector on the example of survey carried out in a mine]. Przegl Górniczy. 2013;69(4):54-9. Polish.

3. Kruszyński K. [Psychologist in the mining plant]. In: [Proceedings of XX School of Underground Mining]; 2006 Feb 20-23; Szczyrk, Poland. Kraków: School of Underground Mining; 2006. p. 1043-7. Polish.

4. Niczyporuk Z. Safety management in coal mines - Risk assessment. Int J Occup Saf Ergon. 1996;2(3):243-50, https:// doi.org/10.1080/10803548.1996.11076352.

5. Gabryelewicz I, Sadłowska-Wrzesińska J, Kowal E. Evaluation of safety climate level in a production facility. Procedia Manuf. 2015;3(1):5822-9, https://doi.org/10.1016/j.promfg. 2015.07.835.

6. Buchowiecka A, Grzenia A, Felczykowska A, Sadowska H, Żeromska-Mielniczuk D. [Accidents at work in 2017]. Warszawa, Gdańsk: Statistics Poland, Statistical Office in Gdańsk, Centre for Working Condition Statistics; 2018. Polish
7. Mien T. Mine waste water management and treatment in coal mines in Vietnam. Geosyst Eng. 2012;15(1):66-70, https://doi.org/10.1080/12269328.2012.674430.

8. Homer AW. Coal mine safety regulation in China and the USA. J Contemp Asia. 2009;39(3):424-39, https://doi. org/10.1080/00472330902944511.

9. Bagherpour R, Yarahmadi R, Khademian A. Safety risk assessment of Iran's underground coal mines based on preventive and preparative measures. Hum Ecol Risk Assess. 2015;21(8):2223-38, https://doi.org/10.1080/10807039. 2015.1046418.

10. Piekarski C, Seyl G, Bardeleben J. State of miners' health in Germany. Appl Occup Environ Hyg. 1997;12(12):815-9, https://doi.org/10.1080/1047322X.1997.10390615.

11. Mhlongo SE, Amponsah-Dacosta F. A review of problems and solutions of abandoned mines in South Africa. Int J Min Reclam Environ. 2016;30(4):279-94, https://doi.org/10.1080/ 17480930.2015.1044046.

12. Konopko W. [Occupational safety in mining. Mining and environment]. Katowice: Główny Instytut Górnictwa; 2013. Polish.

13. Łuczak A. [Psychophysical requirements in the selection of people for difficult and hazardous occupations]. Warszawa: Centralny Instytut Ochrony Pracy; 2001. Polish.

14. Grzesik J. [Problems in medical care of miners. Papers presented at mining conferences, Institute of Occupational Medicine and Environmental Health]. Sosnowiec: Instytut Medycyny Pracy i Zdrowia Środowiskowego; 2011. Polish.

15. Cox T, Griffiths A, Leka S. Work organization and workrelated stress. In: Gardiner K, Harrington JM, editors. Occupational hygiene. Oxford: Blackwell Publishing; 2005. p. 421-32, https://doi.org/10.1002/9780470755075.ch28.

16. European Agency for Safety and Health at Work (EU-OSHA). Expert forecast on emerging psychosocial risks related to occupational safety and health. Luxembourg: Office for Official Publications of the European Communities, 2007.

17. Hoel H, Sparks K, Cooper CL. The cost of violence/stress at work and the benefits of a violence/stress-free working 
environment. Geneva: International Labour Organization; 2001.

18. Sadłowska-Wrzesińska J. Analysis of psychosocial risk in the context of the objectives of macroergonomics. In: Vink P, editor. Advances in social and organizational factors. Proceedings of the 5th International Conference on Applied Human Factors and Ergonomics; 2014 Jul 19-23; Kraków, Poland. AHFE Conference; 2014. p. 277-85.

19. Ogińska-Bulik N. [Occupational stress in social service occupations. Sources - Consequences - Prevention]. Warszawa: Difin; 2006. Polish.

20. Litzke SM, Schuh H. [Stress, mobbing and burnout]. Gdańsk: Gdańskie Wydawnictwo Psychologiczne; 2007. Polish.

21. Potocka A. [Psychosocial risk in the workplace - Introduction to the issue]. In: Merecz-Kot D, editor. [Prevention of psychosocial risk at work - From theory to practice]. Lódź: Wydawnictwo IMP; 2011. p. 23-44. Polish.

22. Mościcka-Teske A, Potocka A. [Psychosocial Risks Scale. User manual]. Łódź-Gdańsk: Wydawnictwo NSZZ Solidarność; 2014. Polish.

23. Tiwari SK, Mishra PC. Work stress and health as predictors of organizational commitment. J Ind Acad Appl Psychol. 2008;34(2):267-77.

24. Michael O, Court D, Petal P. Job stress and organizational commitment among mentoring coordinators. Int J Educ Manage. 2009;23(3):266-88, https://doi.org/ 10.1108/09513540910941766.

25. Nasr L. The relationship between the 3 components model of commitment, workplace stress and career path application to employees in medium size organizations in Lebanon. J Organ Culture Commun Conflict. 2012;16(1):71-87.

26. Babin BJ, Boles JS. The effects of perceived co-worker involvement and supervisor support on service provider role stress, performance, and job satisfaction. J Retailing. 1996;72(1): 67-76, https://doi.org/10.1016/S0022-4359(96)90005-6.

27. Fu G, Lu B, Chen X. The model of organization safety management base on behavioral science. China Saf Sci J. 2005;15(9):21-4.

28. Amponsah-Tawiah K. Examining psychosocial and physical hazards in the Ghanaian mining industry and their implications for employees' safety experience. J Safety Res. 2013;45(1):75-84, https://doi.org/10.1016/j.jsr.2013. 01.003 .

29. Ishtiaq M. Jehan N, Rehman ZU, Rabnawaz, Akbar S, Sardar $\mathrm{M}$, et al. Factors associated with occupational injuries in coal miners. J Med Sci. 2014;22(1):21-4.

30. Liu G, Luo C. Analysis of the safety psychological factors in the coal mine safety management. Procedia Eng. 2012;45(4):253-8, https://doi.org/10.1016/j.proeng. 2012.08.153.

31. Ghosh AK, Bhattacherjee A, Chau N. Relationships of working conditions and individual characteristics to occupational injuries: A case-control study in coal miners. J Occup Health. 2004;46(6):470-80, https://doi.org/10.1539/ joh.46.470.

32. Iverson RD, Maguire C. The relationship between job and life satisfaction: Evidence from a remote mining community. Hum Relations. 2000;53(6):807-39, https://doi. org $/ 10.1177 / 0018726700536003$.

33. Bhattacherjee A, Kunar BM. Miners' return to work following injuries in coal mines. Med Pr. 2016;67(6):729-42, https://doi.org/10.13075/mp.5893.00429.

34. Viswesvaran C, Sanchez IJ, Fisher J. The role of social support in the process of work stress: A meta-analysis. J Vocat Behav. 1999;54(2):314-34, https://doi.org/10.1006/ jvbe.1998.1661.

This work is available in Open Access model and licensed under a Creative Commons Attribution-NonCommercial 3.0 Poland License - http://creativecommons.org/ licenses/by-nc/3.0/pl/deed.en. 